\title{
Chlorophyll fluorescence and biomass partitioning within light and nitrogen deficiency: An example of the use of the R programming language for teaching
}

\author{
Junior Pastor Pérez-Molina ${ }^{1}$ (D), Raquel Castro Lara ${ }^{1}$ (D), Ian Portuguez Brenes ${ }^{1}$ (D), Valerie Araya Trejos ${ }^{1}$ \\ (iD) \& Andrey Quesada Traña 1 iD \\ 1. Universidad Nacional, Escuela de Ciencias Biológicas, Laboratorio de Ecología Funcional y Ecosistemas Tropicales \\ (LEFET), Costa Rica; junior.perez.molina@una.ac.cr; raque.1897.rc@gmail.com; arturitoportuguez@gmail.com; \\ varayatre14@gmail.com; andreybioque1599@gmail.com
}

\author{
Recibido 11-IX-2019 • Corregido 27-I-2020 • Aceptado 02-II-2020 \\ DOI: https://doi.org/10.22458/urj.v12i1.2629
}

\begin{abstract}
Introduction: Chlorophyll Fluorescence $(F V / F m)$ detects damage in photosystem II (PSII) in plants exposed to stress (biotic and/or abiotic). Objective: In this context, $\mathrm{Fv} / \mathrm{Fm}$ for the diagnosis of the effect of $N$ deficiency and light in tomato plants (Solanum lycopersicum) was evaluated. Methods: We used the software $\mathrm{R}$ to analyze data from an experiment consisted of two light treatments (high and low) and two Hoagland nutritive solutions ( $N$ deficiency: $(-) N$; and complete solution: $C)$. Twenty tomato plants within the two light treatments, with two nutrient levels $((-) N$ and $C)$ were used. For four weeks, weekly measurements for height $(H)$, leaf number $(N L)$, and $F v / F m$ were made. On the fourth week, the dry mass partitioning (root: $R M R$; stem: $S M R$; and leaves: $L M R$ ) and chlorophyll concentration ( $a$, $b, a / b$, and total) was measured. Results: We found statistically significant differences between treatments for $H, N L$ and $F v / F m(K W>14,5$, g.I. $=3,76, P<0,01)$, but no differences for chlorophyll concentration $(F<2,2 ;$ g.l. $=1$, $16, P>0,05)$. In both light conditions it was higher $L M R$ in $C$ treatment, but with lower $R M R$ compared to $(-) N$. Statistically significant correlations (\% Spearman, $\mathrm{P}<0,05)$ between $F V / F m$ and $L M R, R M R$, and $S M R(-76 \%, 69 \%$, and $37 \%$, respectively) were found. Conclusion: Overall, we can emphasize that the $\mathrm{Fv} / \mathrm{Fm}$ is a sensitive variable to the stress caused by nitrogen and light deficiency, whose progress of stress time-course can assess. Finally, Fv/Fm proved to be an indicator of the dry mass partition of stress induced by $N$ deficiency and could be implemented as diagnostic in breeding programs.
\end{abstract}

Keywords: Chlorophyll fluorescence, dry mass partitioning, nitrogen deficiency, light, tomato.
RESUMEN. "Fluorescencia de clorofila y la partición de biomasa en condiciones de deficiencia de luz y nitrógeno: un ejemplo del uso del lenguaje de programación $\mathrm{R}$ para la docencia". Introducción: La fluorescencia de clorofila (Fv/Fm) detecta el daño en el fotosistema II (PSII) en plantas expuestas a algún tipo de estrés (biótico y/o abiótico). Objetivo: En este contexto, se evaluó la fluorescencia de la clorofila ( $F v / F m)$ para el diagnóstico del efecto de la deficiencia de $\mathrm{N}$ y la luz en Solanum lycopersicum. Métodos: El experimento consistió en dos tratamientos de luz (alta y baja) y dos soluciones de Hoagland ( $\mathrm{N}$ deficiencia: (-) $N$; y solución completa: $C$ ). Durante cuatro semanas se realizó mediciones semanales de altura $(H)$, número de hoja $(N L)$ y Fv/Fm. En la cuarta semana se midió la partición de biomasa seca (raíz: $R M R$; tallo: $S M R$; y hojas: $L M R$ ) y concentración de clorofila. Resultados: Encontramos diferencia estadísticamente significativa entre los tratamientos para $H, N L$ y $F v / F m$ $(P<0,01)$, con excepción de la concentración de clorofila $(P>0,05)$. En ambas condiciones de luz fue mayor $L M R$ en el tratamiento $C$, pero con menor $R M R$ en comparación con $(-) N$. Se encontró correlación estadísticamente significativa $(\mathrm{P}<0,05)$ entre $\mathrm{FV} / \mathrm{Fm}$ y $L M R, R M R$ y $S M R(-$ $76 \%, 69 \%$ y 37\%, respectivamente). Conclusión: En general, podemos enfatizar que el $\mathrm{Fv} / \mathrm{Fm}$ es una variable sensible al estrés causado por la deficiencia de nitrógeno y luz, cuyo progreso puede evaluarse a lo largo del tiempo. Finalmente, Fv/Fm demostró ser un indicador de la partición de la biomasa del estrés inducido por la deficiencia de $\mathrm{N}$ y podría implementarse en el diagnóstico en programas de mejoramiento.

Palabras clave: Fluorescencia de clorofila, partición de masa seca, deficiencia de nitrógeno, luz, tomate. 
In recent years, chlorophyll fluorescence measurements applications have increased in the field of plant physiology research (Dong, Men, Li, Zou, \& Ji, 2019; Küpper et al., 2019; Li, Song, Zhou, Xu, \& Zhou, 2019; Madriaza, Saldaña, Salgado-Luarte, Escobedo, \& Gianoli, 2019; Hussain et al., 2019). Chlorophyll fluorescence can be measured by non-destructive low-cost methods to detect photosystem II (PSII) damage in plants exposed to some type of stress (biotic and/or abiotic) (Baker, 2008; Murchie \& Lawson, 2013). Chlorophyll fluorescence occurs in the first phase of photosynthesis processes where light is absorbed by photosynthetic pigments such as chlorophyll (Ch/) and some accessory pigments in the open reaction centers of PSII (Liu et al., 2004). Structure and concentration pigments play an important role in the efficiency of light capture (Horton \& Ruban, 2004). It is well documented that changes in the content of $C h l a, b$, and $a / b$ ratio are closely related to the adaptation processes to maximize the uptake of light by chloroplasts (Björkman, 1981). In plants stress free conditions, the photosynthetic pigments absorb light energy to promote photosynthesis, a fraction of this dissipated as heat, and the rest is remitted as $\mathrm{Ch} /$ fluorescence (Ruban, 2016). Chl fluorescence has a direct relationship to final process of assimilation of C, and could be used to measure plants photosynthetic apparatus efficiency to convert light into chemical energy (Enríquez \& Borowitzka, 2010; Bettini et al., 2016).

Nitrogen $(\mathrm{N})$ is one of the essential macronutrients required for plants growth and development as it is the main constituent of amino acids (Singh, Kumar, Singh, \& Prasad, 2014; Singh, Singh, \& Prasad, 2016), enzymes (e.g.: nitrate reductase, glutamine synthetase, glutamate dehydrogenase, etc.) (Singh et al., 2016), and core photosynthetic pigments, i.e. Chl $a$ and $b$ (both formed by a pyrrole ring structure of $\mathrm{N}$ with a $\mathrm{Mg}$ as central atom). $\mathrm{N}$ in plants also acts as a signaling element that affects the expression of numerous genes; these participate in the regulation of processes such as the rate assimilation of $\mathrm{N}$ and $\mathrm{C}$, carbohydrates metabolism, and as defense antioxidant systems against biotic or abiotic stress, among others (Singh et al., 2014; Singh et al., 2016). Therefore, it is expected that a $\mathrm{N}$ deficiency results in the foliar level a decrease in soluble sugars, starch, proteins, nitrates, Chl (Cai et al., 2012; Hussain, Khan, Cao, Wu, \& Geng, 2016), and an increased of reactive oxygen species (Lin, Chao, Huang, \& Kao, 2011). Nitrogen availability of plays an important role in the synthesis of photosynthetic pigments, which is modulated by the availability of light. Here, we hypothesized that $\mathrm{N}$ deficiency conditions could be attenuated under low light conditions.

Relationships between $\mathrm{Ch} /$ fluorescence and primary gross production has stimulated a flurry of research (Gu, Han, Wood, Chang, \& Sun, 2019). To our knowledge, there is limited information about the link between chlorophyll fluorescence and dry mass partitioning of plants under nitrogen deficiency conditions. Nitrogen deficiency can affect the biosynthesis of enzymes (Bernard \& Habash, 2009; Ortigosa, Valderrama-Martín, Ávila, Cánovas, \& Cañas, 2019) which are necessary to repair damage to the membrane of thylakoids in the reaction center of PSII; this damage causes a fall in $\mathrm{Ch} /$ fluorescence, which manifests as a carbohydrate synthesis reduction and consequently alters the root-to-leaf ratio (root system increase in the search for $\mathrm{N}$ ). We hypothesize that plants with $\mathrm{N}$ deficiency invest more growth in the radical system affecting the leaf.

Solanum lycopersicum L. (tomato) is among the most important and widely traded vegetable crops in the world and has a central position in the human diet as source of vitamins, carbohydrates, proteins, and mineral nutrients (Seddon et al., 1994; Szeto, Tomlinson, \& Benzie, 2002). Tomato plants exhibit rapid growth and differential dry mass accumulation in response to changes to nitrogen supply (Ortigosa et al., 2019). Tomato was used as a model plant to study of Chl fluorescence application for diagnosis of effect $\mathrm{N}$ and light deficiency. We evaluated growth, dry mass partitioning, and $\mathrm{Chl}$ concentration of tomato grown in a greenhouse. Finally, due to the research project has been developed in the frame of a "Plant Anatomy and Physiology" course for students of the second year of Biology Degree in Universidad Nacional, Costa Rica, it was made a 
GitHub repository for access to $R$ script, database, and statistical results. This can be used to elaborate scientific analysis reports, for teaching in order to aid students' data interpretation and to increase scientific communication skills.

\section{MATERIALS AND METHODS}

Study area: The research was conducted between October and December 2018 in the greenhouse of the Laboratory of Functional Ecology and Tropical Ecosystems (LEFET), National University of Costa Rica, Heredia. According to IMN (2019), average monthly temperature, precipitation, and relative humidity of air during the study period were between $19,5-20^{\circ} \mathrm{C}, 184,2-$ $441 \mathrm{~mm}$, and $83-88 \%$ (max.-min.), respectively.

Experimental design, plant material, and growth conditions: The experiment consisted of two light treatments in the greenhouse (onwards called as high and low, 439,8 $\pm 12,1$ standard error (SE) and 70,3 $\pm 3,7 \mathrm{SE} \mu \mathrm{mol} \mathrm{m} \mathrm{m}^{-2} \mathrm{~s}^{-1} P P F D$, respectively) and two Hoagland solutions ( $\mathrm{N}$ deficiency: (-)N; and complete solution: $C$ ). Solution $C$ consisted of $20 \mathrm{~mL}$ of $\mathrm{KNO}_{3}, \mathrm{KH}_{2} \mathrm{PO}_{4}, \mathrm{MgSO}_{4}$, and $30 \mathrm{~mL}$ of $\mathrm{Ca}\left(\mathrm{NO}_{3}\right)_{2}$, and the (-) N solution in $20 \mathrm{~mL}$ of $\mathrm{KH}_{2} \mathrm{PO}_{4}, \mathrm{MgSO}_{4}$, and $\mathrm{KCl}$, and $30 \mathrm{~mL}$ of $\mathrm{CaCl}_{2}$. In both cases, a complete solution of micronutrients ( $\mathrm{g} \mathrm{L}^{-1}: 2,86 \mathrm{H}_{3} \mathrm{BO}, 1,81 \mathrm{MnCl}_{2}\left(\mathrm{H}_{2} \mathrm{O}\right)_{4}, 0,22 \mathrm{ZnSO}_{4}\left(\mathrm{H}_{2} \mathrm{O}\right)_{7}, 0,08$ $\left.\mathrm{CuSO}_{4}\left(\mathrm{H}_{2} \mathrm{O}\right)_{5}, 0,02 \mathrm{H}_{2} \mathrm{MoO}_{4}\left(\mathrm{H}_{2} \mathrm{O}\right)\right)$ and distilled water was added to obtain a final volume of $10 \mathrm{~L}$. We used 80 healthy plants of $S$. Iycopersicum (cv. Hay Slip) previously acclimated in the greenhouse for a week with a similar number of leaves and height (5-6 leaf and 6,5 $\pm 0,3 \mathrm{~cm}$, respectively). Within the two light treatments, with two nutrient solution levels, 20 plants were randomly assigned for each light-deficiency treatment combination. Each plant was placed in a glass container with $100 \mathrm{~mL}$ of the corresponding solution; periodically the solution was changed to avoid $\mathrm{pH}$ changes and contamination by algae and/or fungi. Weekly measurements of height $(H$, from first lateral root to apex meristem), number of leaf ( $N L$, young leaf in the meristem apical and mature) and maximum photochemical efficiency (quantum yield, $\mathrm{Fv} / \mathrm{Fm}$ ) of open reaction centers II (RCIls) (Cosgrove \& Borowitzka, 2010), were measured. $F v / F m=[F m-F o] / F m$, where $F o$ is the minimum and $F m$ is the maximum fluorescence yield (Baker \& Rosenqvist, 2004). Fv/Fm was measured using a photosynthesis yield analyzer (model MINI-PAM-II/R, Heinz Walz GmbH, 91090 Effeltrich, Germany) in plants that were 15 to $20 \mathrm{~min}$. in darkness on a leaf completely expanded by the plant, located in the first pair from the basal part of the plant. Mature leaves were selected on the rationale that $\mathrm{N}$ is a mobile macroelement that, under deficiency conditions, the plant can easily transfer $\mathrm{N}$ from the mature leaves to the young ones. After the fourth week of growth, dry mass of root (RDM), leaf $(L D M)$, shoot (SDM) and total (TDM) of 15 plants were obtained for each combination of lightdeficiency treatment (dry mass was obtained at $60^{\circ} \mathrm{C}$ for $72 \mathrm{~h}$ ). Dry mass partitioning as RDM-to$T D M$ ratio $(R M R), L D M$-to-TDM ratio $(L M R), S D M$-to-TDM ratio $(S M R), R D M$-to- $L D M$ ratio $(R L R)$, and $R D M$-to-aboveground dry mass ratio $(R B A)$ were calculated. Finally, in the fourth week of growth, combinations of light-deficiency treatment, the concentration of leaf chlorophyll (Chl) $a, b, a / b$ ratio, and total were measured for each of five plants. The concentration of leaf chlorophyll was measured by the spectrophotometry in a set of leaves per plant, for this each plants was macerated with $80 \%$ acetone $(3 \mathrm{~mL}), \mathrm{CaCO}_{3}$ (one pinch), and then centrifuged for 30s. Chl $a, b$, and total concentration was calculated by the following equation (Eq. 1, 2, and 3, respectively) (Lichtenthaler, 1987), where $A$ is the absorbance (646 and $663 \mathrm{~nm}$ ):

$$
\begin{aligned}
\text { Chl }_{a}=\left[\left(12,21 \cdot A_{663}\right)-\left(2,81 \cdot A_{646}\right)\right] \mu g \cdot m L^{-1} & \text { Eq. } 1 \\
\text { Chl }_{b}=\left[\left(20,13 \cdot A_{646}\right)-\left(5,03 \cdot A_{663}\right)\right] \mu g \cdot m L^{-1} & \text { Eq. } 2 \\
\text { Total Chl }=\left[\left(17,32 \cdot A_{646}\right)-\left(7,18 \cdot A_{663}\right)\right] \mu g \cdot m L^{-1} & \text { Eq. } 3
\end{aligned}
$$


Data analysis: $H, N L$, and $F v / F m$ were evaluated by Kruskal-Wallis analysis (KW) for each week ( 1 to 4 weeks) for all combinations of light-deficiency treatments (Light: high and low; and Deficiency: (-) $N$ and $C$ ), and comparison a posteriori of Fisher's Least Significant Difference (LSD). Dry mass partitioning $(R M R, L M R, S M R, R L R$, and TDM) and concentration of leaf chlorophyll ( $a, b$, $a / b$, and total) were evaluated by nested ANOVA for unbalanced samples with Light as main factor and nested deficiency within light factor (Deficiency/Light) and comparison a posteriori of Fisher's $L S D$. A ternary relationship between $S M R, L M R$, and $R M R$ for all combinations of light-deficiency treatments, were made. In addition, Spearman $\left(r_{s}\right)$ correlations between $R M R, L M R, S M R$, and $\mathrm{Fv} / \mathrm{Fm}$ for all combinations of light-deficiency treatments were performed, and fluorescence analysis between $L M R$ and $R M R$ was made. Multivariate associations among $\mathrm{Fv} / \mathrm{Fm}$ and morphological traits were analyzed using a principal component analysis $(P C A)$. Treatments that produced similar plant responses were clustered using a multivariate technique of grouping analysis according to the method of Tocher, which is based on Euclidean average distances (Rencher, 2003). $P C A$ was performed using the $R$ package factorextra (Kassambara \& Mundt, 2017). All statistical analyses were performed using $R$ programming language, version 3.4.0 (Crawley, 2002; RCoreTeam, 2017 ) with a significance level of $\alpha=0,05$. Finally, a GitHub repository for access to $R$ script, database, and statistical analyses results, was made (DOI: 10.5281/zenodo.3628072).

Ethical, conflict of interest and financial statements: the authors declare that they have fully complied with all pertinent ethical and legal requirements, both during the study and in the production of the manuscript; that there are no conflicts of interest of any kind; that all financial sources are fully and clearly stated in the acknowledgements section; and that they fully agree with the final edited version of the article. A signed document has been filed in the journal archives.

\section{RESULTS}

Chlorophyll fluorescence levels in nitrogen deficiency treatment indicated accumulation of stress in a time-course (reduction of $\mathrm{Fv} / \mathrm{Fm}$ ) with lower of $\mathrm{Fv} / \mathrm{Fm}$ values on high light treatment (Fig. $1 \mathrm{~A})$, despite the fact that chlorophyll concentration levels were constant during the experiment $(F<2$,2; g.l. $=1,16$; $P>0.05)$. In contrast, $C h /$ fluorescence on the complete solution was not variable regardless of the light treatment. Also, $H$ and $N L$ (Fig. 1B and Fig. 1C, respectively) for the fourth week had significant difference between low and high light condition for $C$ solution treatment $(K W>14,5 ;$ g.I. $=3,76 ; \mathrm{P}<0,01)$, contrary to $(-) N$ treatment that showed no significant difference between light conditions, regarless the week on which measures were done.

Regarding dry mass partitioning, in both light conditions $L M R$ in $C$ treatment was higher respect to (-) $N$ treatment, however, $R M R$ was higher in (-) $N$ treatment (Fig. 2). SMR was conservative, showing no significant differences between deficiency treatments for each light condition (Table 1).

The ternary relationship between $S M R, R M R$, and $L M R$, together with $F v / F m$ levels (intensity of color) and TDM (size of the symbols), showed that a higher FV/Fm, provoke higher LMR and TDM, and lower $R M R$, whereas $S M R$ remained with low variability, this was with a range between $10-20 \%$ (Fig. 3A). The variability found by all combinations of light-deficiency treatments for $L M R, R M R$, $T D M$, and $\mathrm{Fv} / \mathrm{Fm}$ were between $30-65 \%, 15-50 \%, 0,5-2 \mathrm{~g}$ DM and 0,2-0,8, respectively. These variabilities were closely correlated $\left(\% r_{s}\right)$ among all the pairs of variables, with the exception between $S M R$ and $L M R$ (Fig. 3B): $R M R$ and $L M R$ showed the highest correlation (91\%), followed by $\mathrm{Fv} / \mathrm{Fm}$ and $R M R(-76 \%), F v / F m$ and $L M R(68 \%)$, and finally $S M R$ with $\mathrm{Fv} / \mathrm{Fm}$ and $R M R$ (36 and 37\%, respectively). 

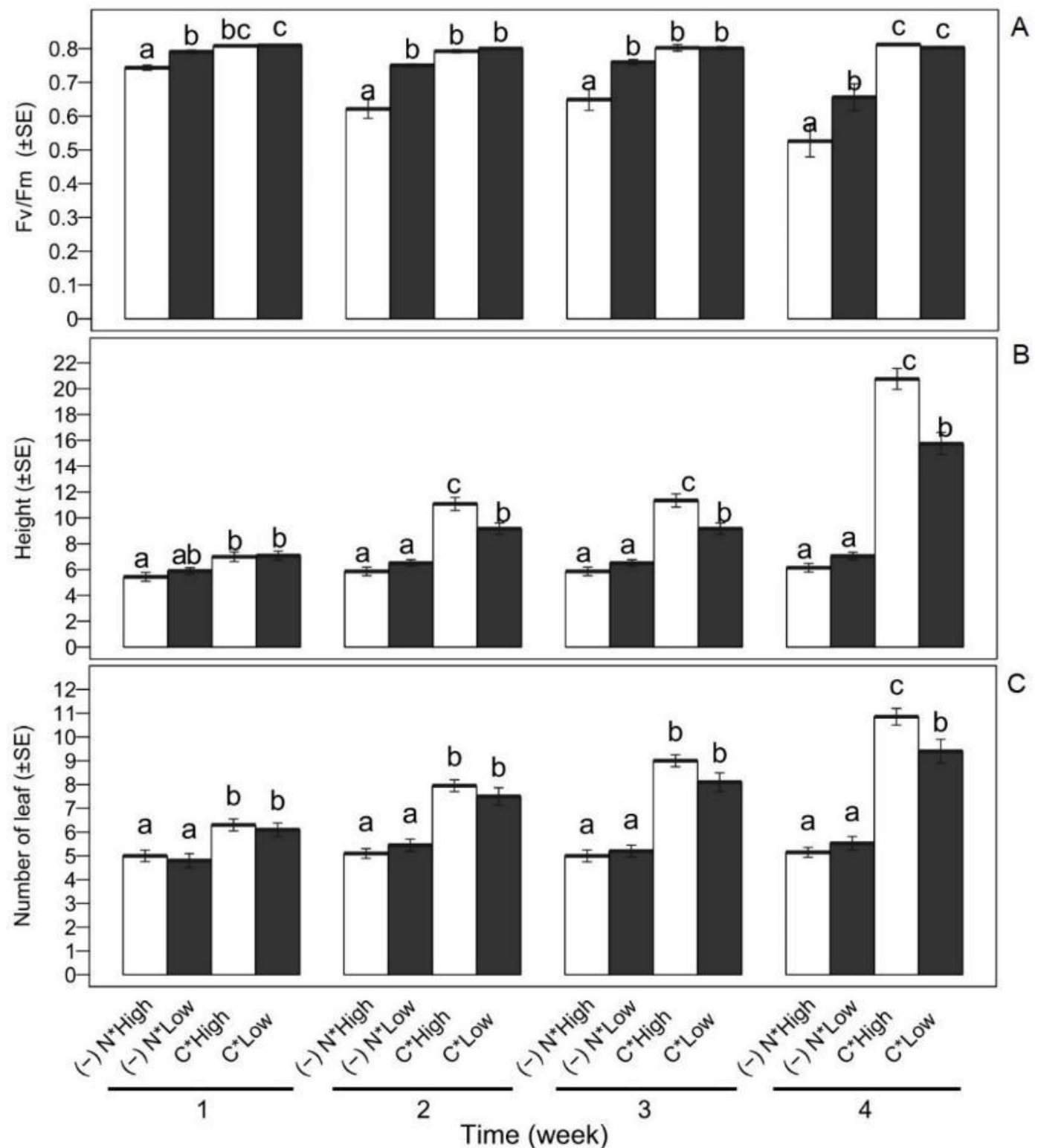

Fig. 1. Chlorophyll fluorescence (A), height $(\mathrm{cm}, \mathrm{B})$, and number of leaf (C) for all combinations of light-deficiency treatments ((-)N: nitrogen deficiency; $C$ : complete solution; light: High and Low), from four weeks of growth of $S$. lycopersicum. Equal letters indicate no statistically significant difference between treatment combinations within each week (Fisher's LSD, $\mathrm{P}<0,05$ ). SE: Standard error.

High correlation between $R M R$ and $L M R$ was adjusted to a linear regression model (Fig. 4), here three important points are shown: (i) the slope of linear regression $(0,875 \pm 0,044 \mathrm{SE}, t=51,83$, $\mathrm{df}=56, \mathrm{P}<0,001)$ reflect the $R D M$-to- $L D M$ ratio $(R L R)$; (ii) the ellipsis at $95 \%$ interval confidence, shows separation between deficiency treatments ( $C$ or $(-) N)$, except for (-) $N^{*}$ Low treatment, which showed greater dispersion range; and (iii) at higher Fv/Fm and $L M R$, this reflect lower $R M R$. 


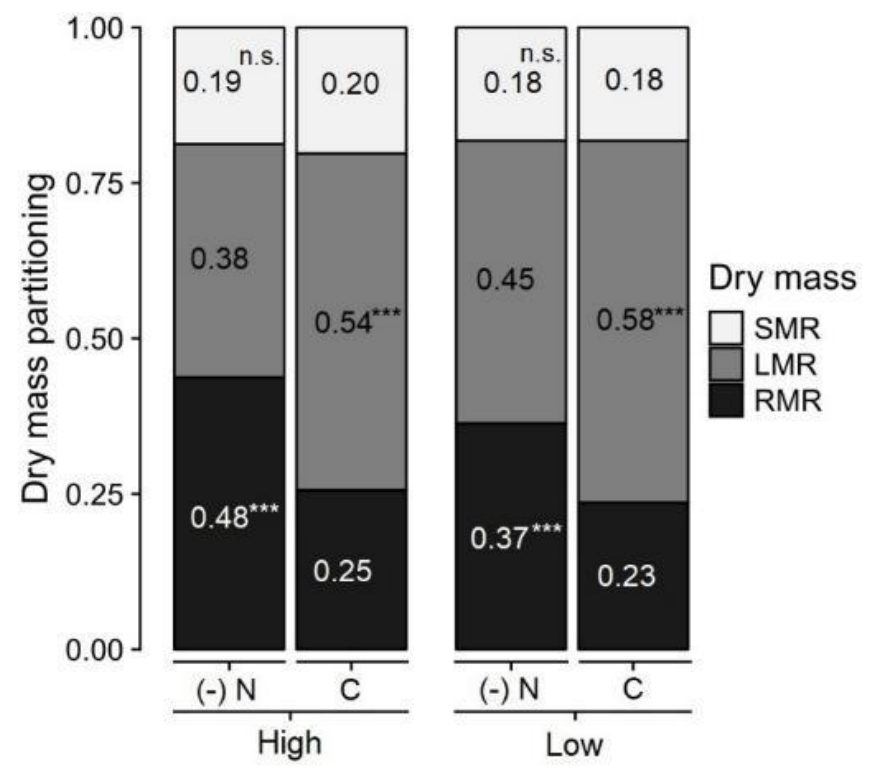

Fig. 2. Dry mass partitioning for all combinations of light-deficiency treatments ((-)N: nitrogen deficiency; $C$ : complete solution; light: High and Low), from the fourth week of growth of S. lycopersicum. SMR: shoot-to-total dry mass ratio; LMR: leaf-to-total dry mass ratio; and $R M R$ : root-to-total dry mass ratio. ${ }^{* * *}: \mathrm{P}<0,001$, asterisks' position inside deficiency treatment ((-) $N$ or $C$ ) by each light levels (High or Low) and dry mass partitioning, marks greater trend and statistically significant difference between deficiency treatment (Fisher's $L S D, P<0,05$ ), n.s.: not significant. Statistical analyses are given in Table 1.

\section{TABLE 1}

Nested ANOVA for variables of dry mass partitioning of S. lycopersicum under two deficiency treatment (Deficiency: N deficiency and Complete) with two light levels (Light: high and low) in the fourth week of plant growth

\begin{tabular}{|c|c|c|c|c|c|c|c|c|c|}
\hline \multirow{2}{*}{ Variable (Abbrev.) } & \multirow{2}{*}{ Light } & \multirow{2}{*}{$\begin{array}{c}\text { Deficiency/Lig } \\
\text { ht }\end{array}$} & \multicolumn{2}{|c|}{ High } & \multicolumn{2}{|c|}{ Low } & \multirow[t]{2}{*}{$\boldsymbol{F}$} & \multirow[t]{2}{*}{$R^{2}{ }_{a d j}$} & \multirow[t]{2}{*}{$P$} \\
\hline & & & $(-) N$ & C & $(-) N$ & C & & & \\
\hline Root-to-total dry mass (RMR) & $* * *$ & $* * *$ & $*$ & & $*$ & & 91,9 & 0,83 & $* * *$ \\
\hline Leaf-to-total dry mass (LMR) & $* * *$ & $* * *$ & & $*$ & & $*$ & 81,4 & 0,81 & $* * *$ \\
\hline Shoot-to-total dry mass (SMR) & n.s. & n.s. & n.s. & & n.s & & 1,7 & 0,03 & n.s. \\
\hline Root-to-leaf dry mass (RLR) & $* * *$ & $* * *$ & $*$ & & $*$ & & 97,1 & 0,84 & $* * *$ \\
\hline Total dry mass (TDM) & $* * *$ & $* * *$ & & $*$ & & $*$ & 187,1 & 0,91 & $* * *$ \\
\hline
\end{tabular}

*: $\mathrm{P}<0,05 ; * * *: \mathrm{P}<0,001$; asterisks' position inside columns (-) $N$ or $C$ for each light treatment (high or low) marks greater trend; $n$.s.: not significant; F: Fisher's value; $R^{2}$ adj: adjusted determination coefficient; P: probability model; $\mathrm{n}=60$. 


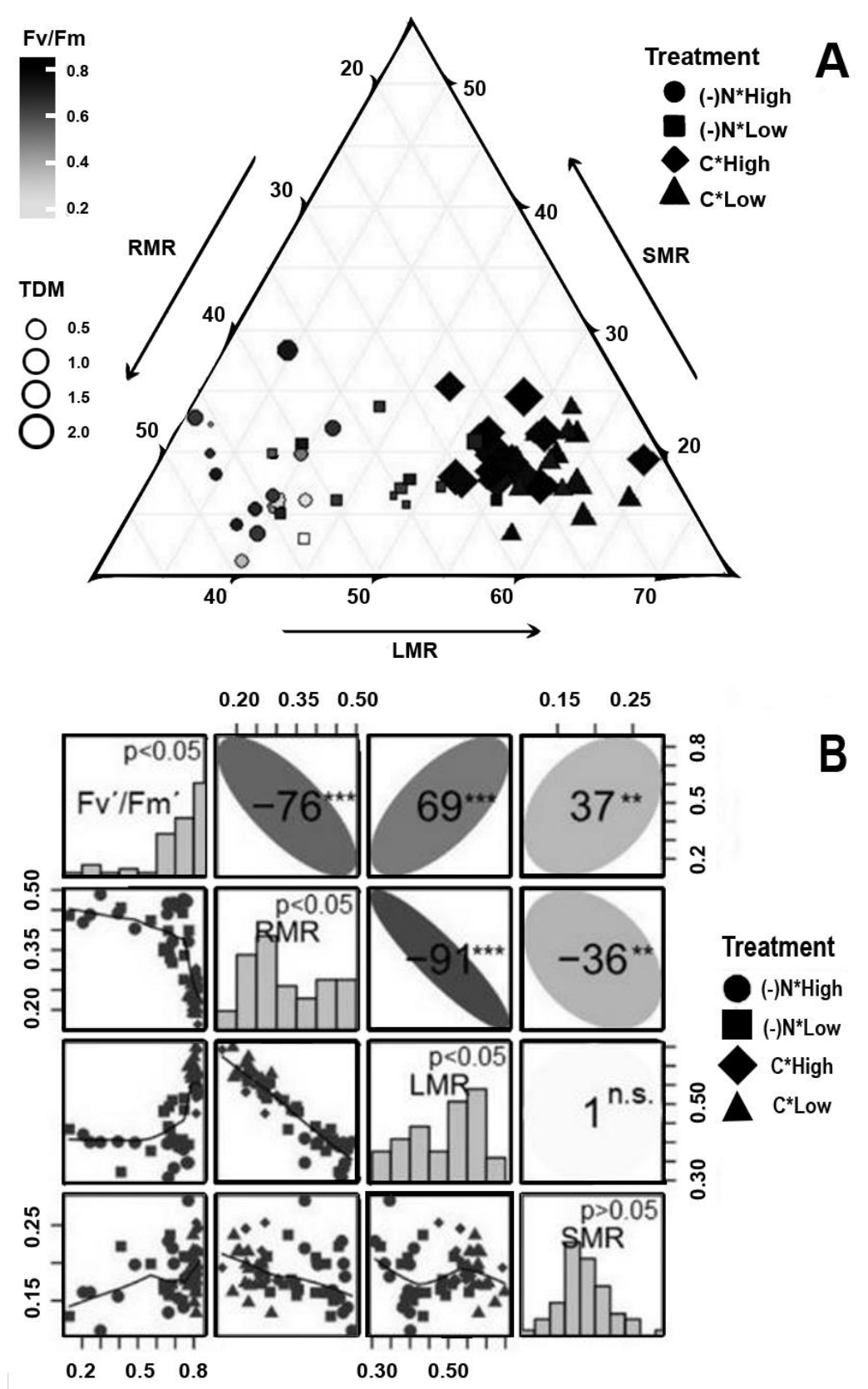

Fig. 3. A) Ternary relationship between $S M R$ (shoot-to-total dry mass ratio), $L M R$ (leaf-to-total dry mass ratio), and $R M R$ (root-to-total dry mass ratio) for all combinations of light-deficiency treatments ((-)N: nitrogen deficiency; $C$ : complete solution; light: High and Low), from fourth week of growth of S. lycopersicum. The size of the symbols is proportional to the total dry mass (TDM), and the intensity of black color to white indicates the levels of $\mathrm{Ch} /$ fluorescence $(F v / F m)$. B) Relationship between $F v / F m, R M R, L M R$, and $S M R$. Subplots on the diagonal represents the histograms frequency of the variables with Shapiro-Wilks test $(\alpha=0,05)$ for all treatment combinations. Subplots above the diagonal represents Spearman correlation coefficients $\left(\%, r_{s}\right)$ between pairs of variables for all treatment combinations, where ellipse represents $r_{s}, * *: \mathrm{P}<0,01 ; * * *: \mathrm{P}<0,001$; and n.s.: not significant. Subplots below the diagonal represents dispersion relationship between pairs of variables.

Finally, the first two axes of a principal component (PC) analysis for all light-deficiency treatment combinations revealed the clear separation between deficiency treatment in the PC1 $(65,2 \%$ variability explained, Fig. 5A). The PC2 $(17,2 \%)$ did not showed any separation between 
groups. Separation between treatments was mainly explained by $L M R, R M R, N L, H$, and Fv/Fm (Fig. $5 \mathrm{~B}) . S M R$ and $R B A$ showed no correlation to separation of treatment groups.

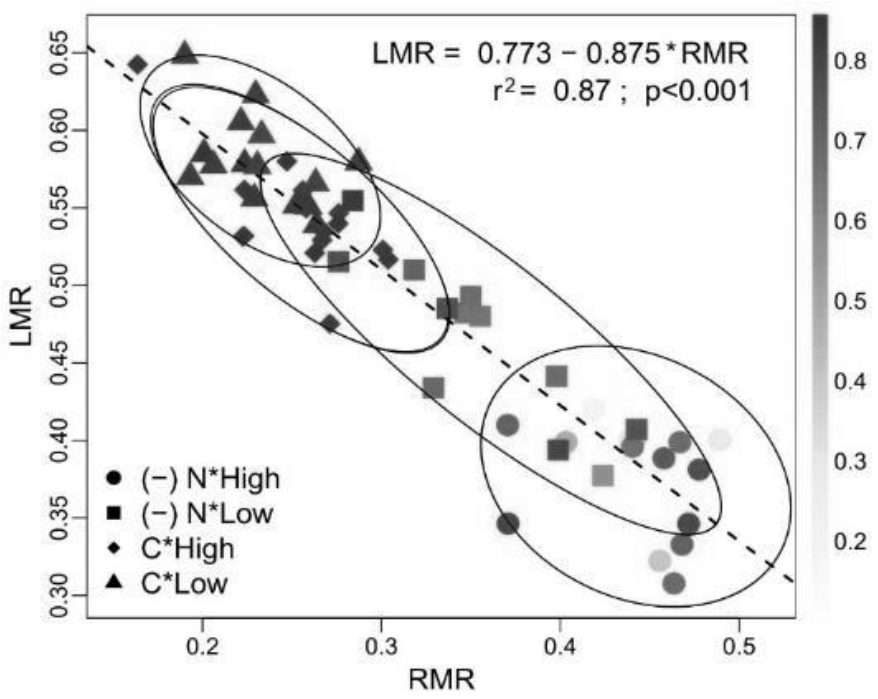

Fig. 4. Relationship between $L M R$ (leaf-to-total dry mass ratio) and $R M R$ (root-to-total dry mass ratio) for all combinations of light-deficiency treatments ((-)N: nitrogen deficiency; $C$ : complete solution; light: High and Low), from the fourth week of growth of S. lycopersicum. The intensity of black color to white indicates Chl fluorescence levels (Fv/Fm). The ellipsis represents the interval confidence $(\alpha=0,05)$ for each treatment-combination.

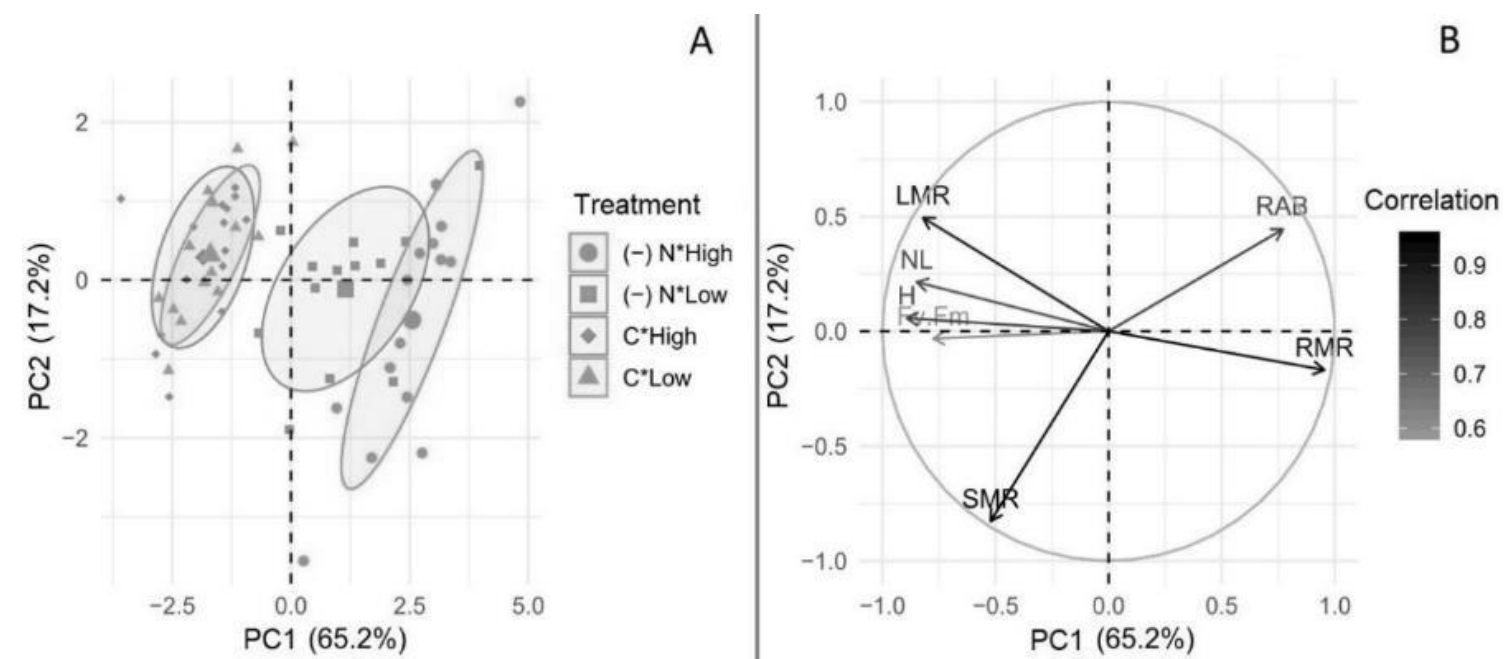

Fig. 5. The first two axes of a principal component (PC) analysis for all combinations of light-deficiency treatments $((-) N$ : nitrogen deficiency; C: complete solution; light: High and Low), from the fourth week of growth of S. lycopersicum. A) Correlation coefficients for all traits are represented by eigenvectors (solid arrows). B) Segregation of the tomato plants following relative scores of the groups based on the four treatment-combinations in relation to the two principal components (PC1 and PC2). The ellipsis represents the interval confidence $(\alpha=0,05)$ for each treatment-combination. 


\section{DISCUSSION}

Nitrogen deficiency under high light conditions increased stress in tomato plant (lower $\mathrm{Fv} / \mathrm{Fm}$ ), due to the fact that this plant has high demands of light for growth (Pan et al., 2019), and if it is exposed to a condition of high demand of photochemical energy absorption, in the absence of $\mathrm{N}$ it can cause the increase of reactive oxygen species (ROS) which in turn damages the synthesis of photoassimilation, enzymes, and hormones requered for healthy growth and development of plants. Nevertheless, an important light condition in this experiment was not used $(44 \%$ light saturation; according to Jiao, Song, Zhang, Du, and Li (2019) and Kaiser et al. (2019), in tomato the value of light saturation is $1000 \mu \mathrm{mol} \mathrm{m} \mathrm{m}^{-2} \mathrm{~s}^{-1}$ PPFD approximately). Under these circumstances, we can infer that $\mathrm{Chl}$ fluorescence was a truly sensitive variable to the stress caused by the deficiency of nitrogen and light, whose progress of stress over time can be valued. We can conclude the role of nitrogen in a culture of full sun conditions, where its deficiency even under non-saturating light conditions can have negative effects in the tomato plants.

Respect to dry mass partitioning due to the effects of nitrogen deficiency, this was similar to those widely documented: (i) a reduction in leaf area ( $L M R$ ) accompanied by a significant increase in root growth (RMR) (Ortigosa et al., 2019), this as a compensatory strategy to search for nitrogen by the radical system; (ii) a significant reduction in the overall growth of the plant as a result of the decrease in the synthesis of hormone, enzyme, and essential amino acid precursors for photosynthesis and/or plant growth; and finally, (iii) under prolonged conditions of nitrogen deficiency chlorosis occurs, followed by foliar necrosis, foliar abstention, and finally death of the plant. This last condition was not registered in the plants since the experiment was not prolonged with this objective. It is important to note that, in this investigation, the nitrogen deficiency the $R M R$ under high light condition was $11 \%$ higher than in low light, and inversely and/or compensatory the $L M R$ was $8 \%$ lower under high light compared to low light. While SMR was conserved as well as some studies (between $17,6 \%$ and $23,4 \%$ in Pan et al. (2019)), the plant will always direct the same proportion of resources to components air support structure component (in this investigation between $18 \%$ and $20 \%$ ).

This study has succeeded on describing a link between chlorophyll fluorescence and dry mass partitioning of plants under nitrogen deficiency conditions. It is expected that plants in nitrogen deficiency invest more growth on the radical system $(R M R)$ in the deterioration of the leaf area $(L M R)$. Both $L M R$ and $R M R$ variables were clearly correlated with to levels of chlorophyll fluorescence. It was even possible to separate the nitrogen deficiency effects and complete solution, with the exception of $(-) N^{*}$ Low treatment, which potentially indicates that low light can reduce the effect of nitrogen deficiency. We hypothesize that nitrogen deficiency affects the integrity of the photosynthetic machinery in different ways (de Groot, van den Boogaard, Marcelis, Harbinson, \& Lambers, 2003): (i) the absence of nitrogen affects the synthesis of enzymes required to repair the PSII reaction centers (RCs) in the thylakoid membrane (Ortigosa et al., 2019), (ii) at the same time as the damage in RCs increases, the accumulation of reactive oxygen species occurs $\left(\mathrm{H}^{+}\right.$, probably a product of photoinhibition stress) (Shin, Berg, \& Schachtman, 2005), increasing the damage in the membrane of the thylakoids; therefore, this damage causes a fall in $\mathrm{Fv} / \mathrm{Fm}$, which then (iii) the reduced integrity of the photosynthetic machinery to generating photochemical energy (e.i. ATP+P and $\mathrm{NAPH}^{+}-\mathrm{H}^{+}$) required to carry out carbohydrate synthesis is interrupted, consequently possibly genes and/or specific hormones are activated for growth of the root system in the search for nitrogen (Ortigosa et al., 2019). Finally, the root/leaf ratio is altered. In this way, we conclude that 
$\mathrm{Ch} /$ fluorescence can be an indicator for the biomass partition stress induced by $\mathrm{N}$ deficiency and low light can attenuate the effect of nitrogen deficiency.

As recommendations for future experiments, we emphasize the importance of studying the effect of nitrogen deficiency in $\mathrm{Chl}$ fluorescence under concentration gradient of nitrogen and light, in order to quantify the interaction between both. Likewise, to evaluate the dry mass partitioning variables at different growth stages of the plants, including the reproductive one, this could change the relevance of the allocation of resources among the different compartments of the plant (leaves, root, stem, and fruit). Finally, we know that this short investigation was done under experimental conditions of laboratory and hydroponic medium, which leaves us to questioning if the effects are similar in a soil substrate. We faithfully believe that $\mathrm{Chl}$ fluorescence as an effect of nutrient deficiency is still recent and that it deserves to be studied, with the purpose of being used deficiency diagnosis and crop improvement programs.

\section{Educational implications (context and education level)}

The present research project has been developed in the frame of a "Plant Anatomy and Physiology" course for students of the second year of Biology Degree. This course offers to students basic concepts of plant anatomy and physiology, with the aim that the student relates the plant structure to the wide variety of functions that plants must perform to live on different habitats and to understand the ecological relationships between them and their environment. The experience of the project has been coupled to university students as it requires advanced skills and basic knowledge of physiological processes in plants. In the laboratory, different experiments were carried out following the scientific method to demonstrate how to manipulate plants and changes on its morphology due to the influence of environmental factors on them. This project frames the role of nitrogen in plants and allows the development of research techniques (i.e. data collection, analysis, and visualization of results). The R programming commands of all the various packages used in this investigation can be applied to other experiments, plant species, variables and stress factors or treatments, also, a greater number of variables can be included. All this with simple modifications to the original $\mathrm{R}$ code provided in this investigation. This can be used to elaborate scientific analysis reports, for teaching in order to aid students' data interpretation and to increase scientific communication skills. These knowledges are framed within the professional training needed for future biologists in Costa Rica.

\section{ACKNOWLEDGEMENTS}

We thank to the Escuela de Ciencias Biologicas of the Universidad Nacional, Costa Rica, for allowing us the development and conclusion of this investigation. Raúl Soto Rodriguez and Kaliana Vargas Corrales technicians of the Biopreparations of Teaching Laboratory for the preparation of hydroponic plant growth solutions; Narcy Villalobos Sandí of the Laboratorio de Biotecnología de Microalgas for the provision of fluorometer (MINI-PAM-II/R); Roberto A. Cordero Solórzano coordinator of the greenhouse of the LEFET for the space and equipment provided; Alejandra Pérez Enríquez and David Vargas for the technical help in handling and using the equipment; finally, but no less important to Deanna Sekulich and Stefany Solano Gonzalez for revising the English. 


\section{REFERENCES}

Baker, N. R., \& Rosenqvist, E. (2004). Applications of chlorophyll fluorescence can improve crop production strategies: an examination of future possibilities. Journal of Experimental Botany, 55(403), 1607-1621. DOI: $10.1093 / j x b / e r h 196$

Baker, N. R. (2008). Chlorophyll Fluorescence: A Probe of Photosynthesis In Vivo. Annual Review of Plant Biology, 59(1), 89-113. DOI: 10.1146/annurev.arplant.59.032607.092759

Bernard, S. M., \& Habash, D. Z. (2009). The importance of cytosolic glutamine synthetase in nitrogen assimilation and recycling. New Phytologist, 182(3), 608-620. DOI: 10.1111/j.1469-8137.2009.02823.x

Bettini, P. P., Marvasi, M., Fani, F., Lazzara, L., Cosi, E., Melani, L., \& Mauro, M. L. (2016). Agrobacterium rhizogenes rolB gene affects photosynthesis and chlorophyll content in transgenic tomato (Solanum lycopersicum L.) plants. Journal of Plant Physiology, 204, 27-35. DOI: 10.1016/j.jplph.2016.07.010

Björkman, O. (1981). Responses to different quantum flux densities In O. L. Lange P. S. Nobel C. B. Osmond, \& H. Ziegler (Eds.), Physiological Plant Ecology I (pp. 57-107). Berlin, Germany: Springer. DOI: 10.1007/978-3-642-68090-8_4

Cai, J., Chen, L., Qu, H., Lian, J., Liu, W., Hu, Y., \& Xu, G. (2012). Alteration of nutrient allocation and transporter genes expression in rice under N, P, K, and Mg deficiencies. Acta Physiologiae Plantarum, 34(3), 939-946. DOI: $10.1007 / \mathrm{s} 11738-011-0890-\mathrm{x}$

Cosgrove, J., \& Borowitzka, M. A. (2010). Chlorophyll Fluorescence Terminology: An Introduction. In D. J. Suggett, O. Prášil \& M. A. Borowitzka (Eds.), Chlorophyll a Fluorescence in Aquatic Sciences: Methods and Applications (pp. 1-17). Dordrecht, Netherlands: Springer.

Crawley, M. (2002). The R Book (2 ${ }^{\text {nd }}$ ed.). Chichester, U.K.: John Wiley \& Sons Ltd.

de Groot, C. C., van den Boogaard, R., Marcelis, L. F., Harbinson, J., \& Lambers, H. (2003). Contrasting effects of N and P deprivation on the regulation of photosynthesis in tomato plants in relation to feedback limitation. Journal of Experimental Botany, 54(389), 1957-1967. DOI: 10.1093/jxb/erg193

Dong, Z., Men, Y., Li, Z., Zou, Q., \& Ji, J. (2019). Chlorophyll fluorescence imaging as a tool for analyzing the effects of chilling injury on tomato seedlings. Scientia Horticulturae, 246, 490-497. DOI: 10.1016/j.scienta.2018.11.019

Enríquez, S., \& Borowitzka, M. A. (2010). The use of the fluorescence signal in studies of seagrasses and macroalgae. In D. Suggett O. Prášil \& M. Borowitzka (Eds.), Chlorophyll a fluorescence in aquatic sciences: methods and applications (pp. 187-208). Dordrecht, Netherlands: Springer. DOI: 10.1007/978-90-481-9268-7_9

Gu, L., Han, J., Wood, J. D., Chang, C. Y. Y., \& Sun, Y. (2019). Sun-induced Chl fluorescence and its importance for biophysical modeling of photosynthesis based on light reactions. New Phytologist, 223, 1179-1191. DOI: 10.1111/nph.15796

Horton, P., \& Ruban, A. (2004). Molecular design of the photosystem II light-harvesting antenna: photosynthesis and photoprotection. Journal of Experimental Botany, 56(411), 365-373. DOI: 10.1093/jxb/eri023

Hussain, S., Iqbal, N., Brestic, M., Raza, M. A., Pang, T., Langham, D. R., . . Gao, Y. (2019). Changes in morphology, chlorophyll fluorescence performance and Rubisco activity of soybean in response to foliar application of ionic titanium under normal light and shade environment. Science of the Total Environment, 658, 626-637. DOI: 10.1016/j.scitotenv.2018.12.182

Hussain, S., Khan, F., Cao, W., Wu, L., \& Geng, M. (2016). Seed Priming Alters the Production and Detoxification of Reactive Oxygen Intermediates in Rice Seedlings Grown under Sub-optimal Temperature and Nutrient Supply. Frontiers in Plant Science, 7, 439. DOI:10.3389/fpls.2016.00439

IMN. (2019). Instituto Meteorológico Nacional de Costa Rica. Retreived from https://www.imn.ac.cr/en/web/imn/inicio 
Jiao, X.-C., Song, X.-M., Zhang, D.-L., Du, Q.-J., \& Li, J.-M. (2019). Coordination between vapor pressure deficit and CO2 on the regulation of photosynthesis and productivity in greenhouse tomato production. Scientific Reports, 9(1), 8700. DOI: $10.1038 / s 41598-019-45232-w$

Kaiser, E., Ouzounis, T., Giday, H., Schipper, R., Heuvelink, E., \& Marcelis, L. F. M. (2019). Adding Blue to Red Supplemental Light Increases Biomass and Yield of Greenhouse-Grown Tomatoes, but Only to an Optimum. Frontiers in Plant Science, 9(2002). DOI: 10.3389/fpls.2018.02002

Kassambara, A., \& Mundt, F. (2017). factoextra: Extract and Visualize the Results of Multivariate Data Analyses. (R package version 1.0.4.999). Retrieved from https://rpkgs.datanovia.com/factoextra/index.html

Küpper, H., Benedikty, Z., Morina, F., Andresen, E., Mishra, A., \& Trtilek, M. (2019). Analysis of OJIP Chlorophyll Fluorescence Kinetics and QA Reoxidation Kinetics by Direct Fast Imaging. Plant Physiology, 179(2), 369-381. DOI: $10.1104 / p p .18 .00953$

Li, Y., Song, H., Zhou, L., Xu, Z., \& Zhou, G. (2019). Tracking chlorophyll fluorescence as an indicator of drought and rewatering across the entire leaf lifespan in a maize field. Agricultural Water Management, 211, 190-201. DOI: 10.1016/j.agwat.2018.09.050

Lichtenthaler, H. K. (1987). Chlorophylls and carotenoids: pigments of photosynthetic biomembranes. In W. B. Jakoby, S. P. Colowick, \& O. W. Griffith (Eds.), Methods in Enzymology (Vol. 148, pp. 350-382). U.S.A.: Academic Press. DOI: 10.1016/0076-6879(87)48036-1

Lin, Y.-L., Chao, Y.-Y., Huang, W.-D., \& Kao, C. H. (2011). Effect of nitrogen deficiency on antioxidant status and Cd toxicity in rice seedlings. Plant Growth Regulation, 64(3), 263-273. DOI: 10.1007/s10725-011-9567-0

Liu, Z., Yan, H., Wang, K., Kuang, T., Zhang, J., Gui, L., ... Chang, W. (2004). Crystal structure of spinach major light-harvesting complex at 2.72 Å resolution. Nature, 428(6980), 287. DOI: 10.1038/nature02373

Madriaza, K., Saldaña, A., Salgado-Luarte, C., Escobedo, V. M., \& Gianoli, E. (2019). Chlorophyll Fluorescence May Predict Tolerance to Herbivory. International Journal of Plant Sciences, 180(1), 81-85. DOI: 10.1086/700583

Murchie, E. H., \& Lawson, T. (2013). Chlorophyll fluorescence analysis: a guide to good practice and understanding some new applications. Journal of Experimental Botany, 64(13), 3983-3998. DOI: 10.1093/jxb/ert208

Ortigosa, F., Valderrama-Martín, J. M., Ávila, C., Cánovas, F. M., \& Cañas, R. A. (2019). Understanding plant nitrogen nutrition through a laboratory experiment. Biochemistry and Molecular Biology Education, 47(4), 450-458. DOI: 10.1002/bmb.21239

Pan, T., Wang, Y., Wang, L., Ding, J., Cao, Y., Qin, G., ... Zou, Z. (2019). Increased CO2 and light intensity regulate growth and leaf gas exchange in tomato. Physiologia Plantarum. DOI: 10.1111/ppl.13015

RCoreTeam. (2017). R: A language and environment for statistical computing. Vienna: R Foundation for Statistical Computing.

Rencher, A. C. (2003). Methods of Multivariate Analysis (2 ${ }^{\text {nd }}$ ed.). New York, USA.: John Wiley \& Sons, Inc. DOI: $10.1002 / 0471271357$

Ruban, A. V. (2016). Nonphotochemical chlorophyll fluorescence quenching: mechanism and effectiveness in protecting plants from photodamage. Plant Physiology, 170(4), 1903-1916. DOI: 10.1104/pp.15.01935

Seddon, J., Ajani, U., Sperduto, R., Hiller, R., Blair, N., Burton, T., ... Miller, D. (1994). Dietary carotenoids, vitamin-A, vitamin-C, and vitamin-E, and advanced age-related macular degeneration. Jama-Journal of the American Medical Association, 272(18), 1413-1420. DOI: 10.1001/jama.272.18.1413 
Shin, R., Berg, R. H., \& Schachtman, D. P. (2005). Reactive oxygen species and root hairs in Arabidopsis root response to nitrogen, phosphorus and potassium deficiency. Plant and Cell Physiology, 46(8), 1350-1357. DOI: $10.1093 / \mathrm{pcp} / \mathrm{pci} 145$

Singh, M., Kumar, J., Singh, V., \& Prasad, S. (2014). Plant tolerance mechanism against salt stress: the nutrient management approach. Biochemical Pharmacology, 3, e165. DOI: 10.4172/2167-0501.1000e165

Singh, M., Singh, V. P., \& Prasad, S. M. (2016). Responses of photosynthesis, nitrogen and proline metabolism to salinity stress in Solanum lycopersicum under different levels of nitrogen supplementation. Plant Physiology and Biochemistry, 109, 72-83. DOI: 10.1016/j.plaphy.2016.08.021

Szeto, Y. T., Tomlinson, B., \& Benzie, I. F. (2002). Total antioxidant and ascorbic acid content of fresh fruits and vegetables: implications for dietary planning and food preservation. British Journal of Nutrition, 87(1), 55-59. DOI: 10.1079/BJN2001483 